\title{
Effect of Holding Time on the Diffusion Behavior at Interface of Dissimilar Metals Joint between Aluminum and Carbon Steel Joint Using Element Promoter
}

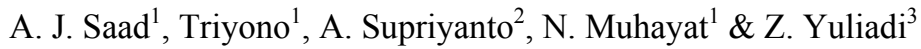 \\ ${ }^{1}$ Mechanical Engineering Department, Sebelas Maret University, Indonesia \\ 2 Physics Department, Sebelas Maret University, Indonesia \\ ${ }^{3}$ Head of Technology Division, PT. PAL Indonesia (Indonesia Ship Industry) \\ Correspondence: Triyono, Mechanical Engineering Department, Sebelas Maret University, Surakarta, Indonesia. \\ Tel: 62-271-632-163. E-mail: triyonomesin@uns.ac.id
}

Received: June 20, 2014 Accepted: July 15, 2014 Online Published: August 3, 2014

doi:10.5539/mas.v8n5p1 URL: http://dx.doi.org/10.5539/mas.v8n5p1

\begin{abstract}
Holding time is used for optimizing the bond diffusion between aluminum Al and Carbon steel SS400. The objective of this research was to investigate the effects of holding time on the interface reactions of diffusion welding between aluminum and carbon steel. Holding time variations of 10, 15, 30 and 45 minutes were applied at $950^{\circ} \mathrm{C}$ using mixture of $\mathrm{Cu}$ and $\mathrm{Fe}$ powder as elements promoter. Single lap joint configuration was performed in vacum furnace to join the dissimilar materials which allowed bonding diffusion. Microstructure was examined on the same test piece. It was found that during diffusion process at $950^{\circ} \mathrm{C}$, the interfacial zone between aluminum and carbon steel substrate features intermetallic layers. The intermetallic thickness increased with increasing the holding time. Crack or incomplete bonding appeared on the specimens with holding time up to 30 minutes and didn't appear on the specimens with holding time of 45 minutes. $\mathrm{Cu}$ rich-element promoter made diffusion penetrated deeper than $\mathrm{Fe}$ rich-element promoter in the same holding time. Macrostructure, microstructure and SEM examinations revealed that Al-steel joint had the best result with element promoter content of $60 / 40 \%$ at 45 minutes holding time. There was no interlayer gap at this specimen. Additionally, from mapping view it can be suggested that in terms of poor interface bonding, $\mathrm{Cu}$ molecules were located just around the interface area, on the other hand, in case of strong interface bonding, $\mathrm{Cu}$ molecules are scattered throughout the specimen. In fact, the position of $\mathrm{Cu}$ molecules can be used as a promising marker for the detection of quality of diffusion joint.
\end{abstract}

Keywords: aluminum, diffusion bounding, interface, steel, holding time, element promoter

\section{Introduction}

Aluminum is the most abundant metal and the third most abundant element in the earth's crust, after oxygen and silicon. It makes up about $8 \%$ by weight of the earth's solid surface. Aluminum is also chemically reactive to occur naturally as free metal (Kobayashi \& Yakou, 2002). There are many applications of Aluminum in our daily life, such as construction machinery, aircraft construction, ship construction, home furnishing and electronics component. For the vehicle industry, Aluminum has established a worldwide position because of its advantages over the other competitive materials.

Because of its lightweight Aluminum provides exceptional unit strengths (strength/density ratio), high corrosion resistance, low maintenance costs, good temperature resistance, ductile which is an intrinsic ability of a material to undergo a certain amount of plastic deformation without the occurrence of macroscopic cracks (Maea et al., 2008). It can be easily joined by all commercial processes such as welding, brazing, or soldering. Aluminum can be easily formed by all common processes, including extrusion (a major advantage) and can be recycled. Beside of the advantages, there are some disadvantages of Aluminum. First, Aluminums is relatively more expensive than steel. Secondly, Aluminum sheets are more difficult to stamp into car body parts. Thirdly, Aluminum is difficult to weld than steel. Lastly, Aluminum doesn't have the strengths levels as steel (Patel et al., 2013). 
The effectiveness of Aluminum choice depends on the nature of the aluminum type used. Properties of low work hardening alloy Al 6061-T 6511, a very high work hardening annealed material $1100 \mathrm{Al}$, and both $\mathrm{Al}$ alloys (Al6061-T6511 and annealed $1100 \mathrm{Al}$ ) were studied and reported in subsequent researches (Khan et al., 2009; 2010a; 2010b). It was reported that the subsequent expansion and positive cross-effect was observed in the a high work hardening alloy annealed $1100 \mathrm{Al}$ as compared to low work hardening alloy Al 6061-T 6511 where contraction and negative cross-effect with finite deformation yield surfaces was showed. According to Khan et al (2010a), the subsequent yield surfaces for annealed Al 1100, the rate of kinematic hardening, Young's and shears moduli decreased and isotropic hardening increased with finite plastic deformation, which showed positive cross-effect for linear, bilinear and non-linear uploading.

Steel is an alloy of iron and a small amount of carbon. Carbon is the primary alloy element, which accounts between $0.002 \%$ and $2.1 \%$ by weight in steel. There is no stiffness advantage in using aluminum over steel. Basically, strength refers to the maximum load that a material can be subjected to without yielding, whereas stiffness refers to how much a material bends when a load is applied (Ajit et al., 2013). Stiffness is quantified by a parameter called Modulus of Elasticity. Steel's modulus is about 3 times stronger than Aluminum but steel's weight is about 3 times heavier than aluminum.

Aluminum welding with other metals is very difficult because there are problems like different melting points, physical natures and other intermetallic differences. Kim et al. (2006) presented that intermetallic diffusion in interface $\mathrm{Al}$ and steel is formed. The Intermetallic Compound For motion (IMC) is rapidly developed and grows between the steel and the melt. Only aluminum diffuses into the steel substrate without the dissolution of iron at the interface of the steel-intermetallic compound. This result was supported by Qiu et al. (2009).

According to Kim et al. (2006) the primary diffusing species of the hot dip aluminizing process in their study was aluminum. Al coating on the steel and the short dipping time prevent the iron from dissolving into the aluminum melt. The IMC is confirmed to be $\mathrm{Fe}_{2} \mathrm{SiAl}_{8}$ with a hexagonal unit cell (space group P63/mmc). Sun and khalel (2007) showed that the intermetallic phases $\mathrm{FeAl}_{2}$ and $\mathrm{Fe}_{2} \mathrm{Al}_{5}$ were the most dominant phases that could be observed, that they were formed sequentially, in contrast to intermetallic, which formed synchronously in bulk materials. A good diffusion interface cannot be formed if the heating temperature is too low, since extent of diffusion is not sufficient even though the holding time is longer and the pressure is larger. But, if the heating temperature is too high, the grains will grow up seriously and the diffusion transition zone can become wider, which will adversely affect the performance of the diffusion bonding joint (Yajiang et al., 2005).

Furthermore, the usage of filler material such as $\mathrm{Cu}-\mathrm{Mg}$ enhance the hardness of interface bonding between two dissimilar metal following by perfect holding time (Mahendran et al., 2009). Therefore, this paper aims to determine the effect of holding time on the diffusion characteristics of the joint with the 6061 aluminum and Carbon steel filler using $\mathrm{Cu}$ and $\mathrm{Fe}$.

\section{Method}

\subsection{Materials and Diffusion Processes}

The used material in this research were aluminum AL 6061 and carbon steel SS400. The chemical composition of the base metals is shown in table 1 and 2 .

Table 1. Chemical Composition of Al 6061 according to Dinaharan et al. (2012)

\begin{tabular}{llllllllll}
\hline $\mathrm{Mg}$ & $\mathrm{Si}$ & $\mathrm{Fe}$ & $\mathrm{Mn}$ & $\mathrm{Cu}$ & $\mathrm{Cr}$ & $\mathrm{Zn}$ & $\mathrm{Ni}$ & $\mathrm{Ti}$ & $\mathrm{Al}$ \\
\hline 0.95 & 0.54 & 0.22 & 0.13 & 0.17 & 0.09 & 0.08 & 0.02 & 0.01 & Bal. \\
\hline
\end{tabular}

Table 2. Chemical composition of SS400 as reported by Dinaharan et al. (2012)

\begin{tabular}{llllllll}
\hline & $\mathrm{Si}$ & $\mathrm{Mn}$ & $\mathrm{P}$ & $\mathrm{S}$ & $\mathrm{Ni}$ & $\mathrm{Cr}$ & $\mathrm{Fe}$ \\
\hline 0.2 & 0.09 & 0.53 & 0.01 & 0.04 & 0.03 & 0.03 & Bal. \\
\hline
\end{tabular}

Joined specimens were cut with length of $30 \mathrm{~mm}$ and width of $30 \mathrm{~mm}$ (Fig. 1). They were joined in single lap joint type and its procedure was based on AWS D8.9. Elements promoter were inserted at interface between aluminum and steel. They were mixture of Al-Fe powder. Two composition were used in this research namely 
$80 \% \mathrm{Fe}-20 \% \mathrm{Cu}$ and $60 \% \mathrm{Fe}-40 \% \mathrm{Cu}$. Diffusion welding of aluminum to steel used a vacuum furnace at $950^{\circ} \mathrm{C}$. The holding time variations were 10, 15, 30 and 45 minutes. Table 3 shows the schedule of diffusion process.

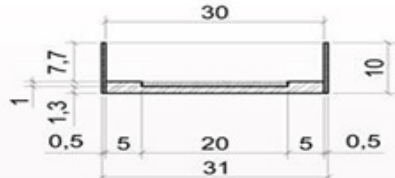

SEC...A - A

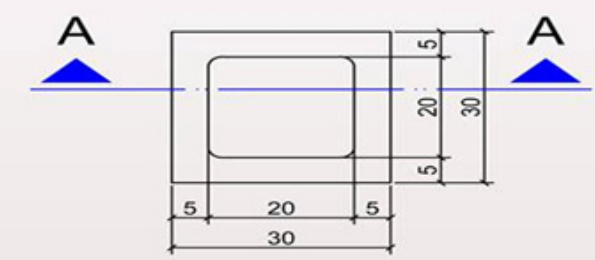

STEEL

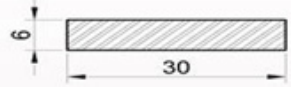

SEC .. B - B

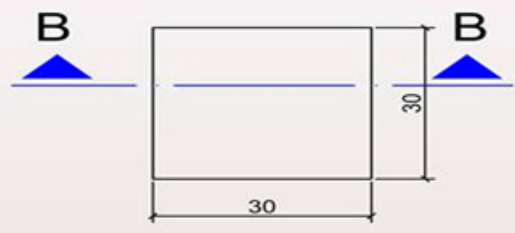

ALMUINUM.

Figure 1. Dimensions of test specimen sizein $\mathrm{mm}$

Table 3. Research parameters variations

\begin{tabular}{lll}
\hline Run No. & Mixture of Elements Promoter & Holding Time (minutes) \\
\hline 1 & $60 \% \mathrm{Fe}-40 \% \mathrm{Cu}$ & 10 \\
2 & $60 \% \mathrm{Fe}-40 \% \mathrm{Cu}$ & 15 \\
3 & $60 \% \mathrm{Fe}-40 \% \mathrm{Cu}$ & 30 \\
4 & $60 \% \mathrm{Fe}-40 \% \mathrm{Cu}$ & 45 \\
5 & $80 \% \mathrm{Fe}-20 \% \mathrm{Cu}$ & 10 \\
6 & $80 \% \mathrm{Fe}-20 \% \mathrm{Cu}$ & 15 \\
7 & $80 \% \mathrm{Fe}-20 \% \mathrm{Cu}$ & 30 \\
8 & $80 \% \mathrm{Fe}-20 \% \mathrm{Cu}$ & 45 \\
\hline
\end{tabular}

\subsection{Joint Characterizations}

The transverse sections of weld passing through the weld interface were prepared by standard metallographic procedure according to ASTM E3-01. The microstructure of mild steel was revealed by using $\mathrm{HNO}_{3} 2.5 \%$ solution while that of aluminum was revealed by using HF 5\%. Microstructure of interface reaction investigations were carried out using an optical microscopy and SEM.

\section{Results}

Diffusion aluminium atom to steel and fero atom to aluminum generally occured at interface of aluminum-steel during diffusion process. Holding time significantly affect the quality of Al-Fe diffusion. Holding time of 10 minutes, 15 minutes, 30 minutes and 45 minutes gave different result of the diffusion as seen in Figure 2. 


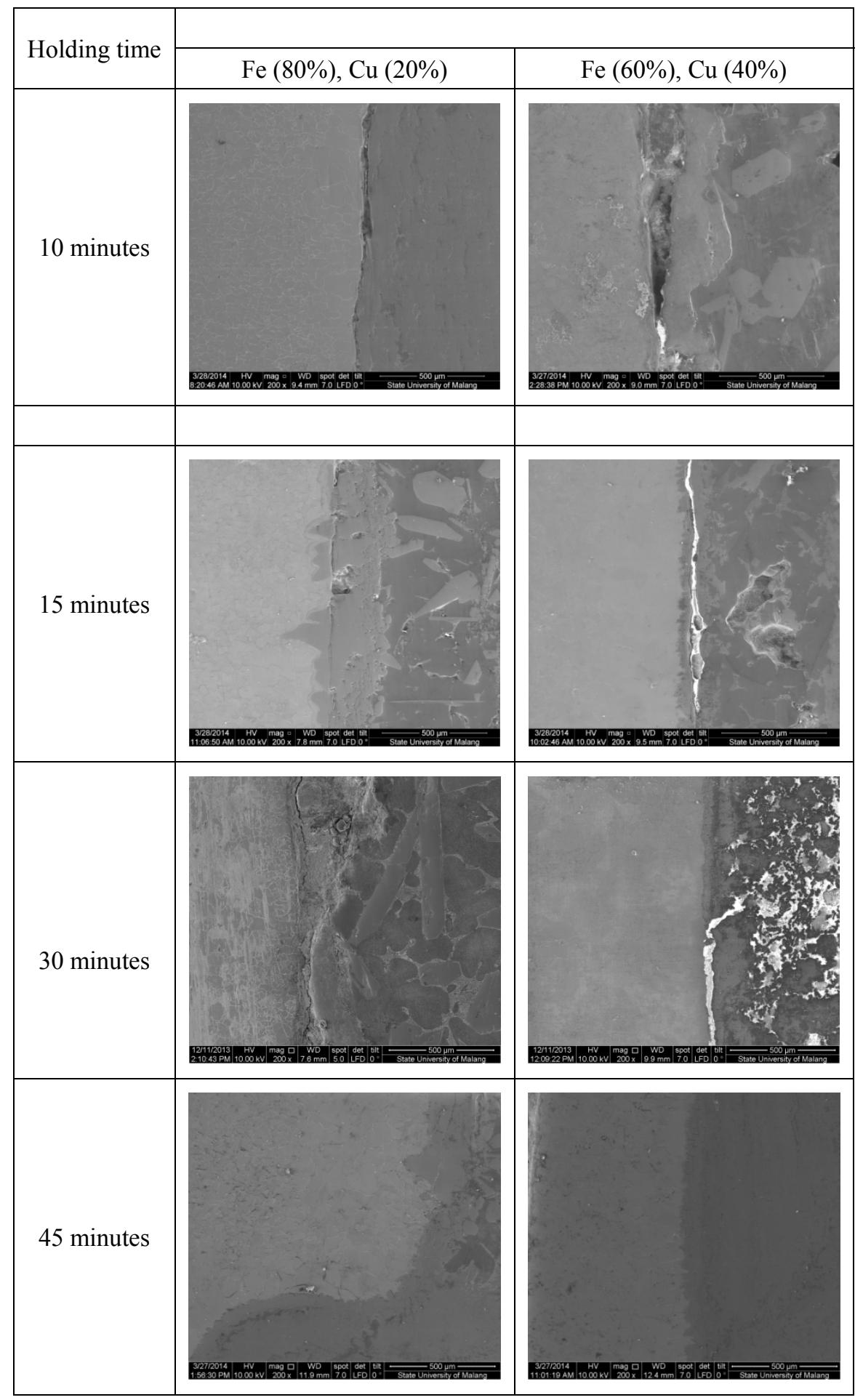

Figure 2. Macrostructure of interface zone 


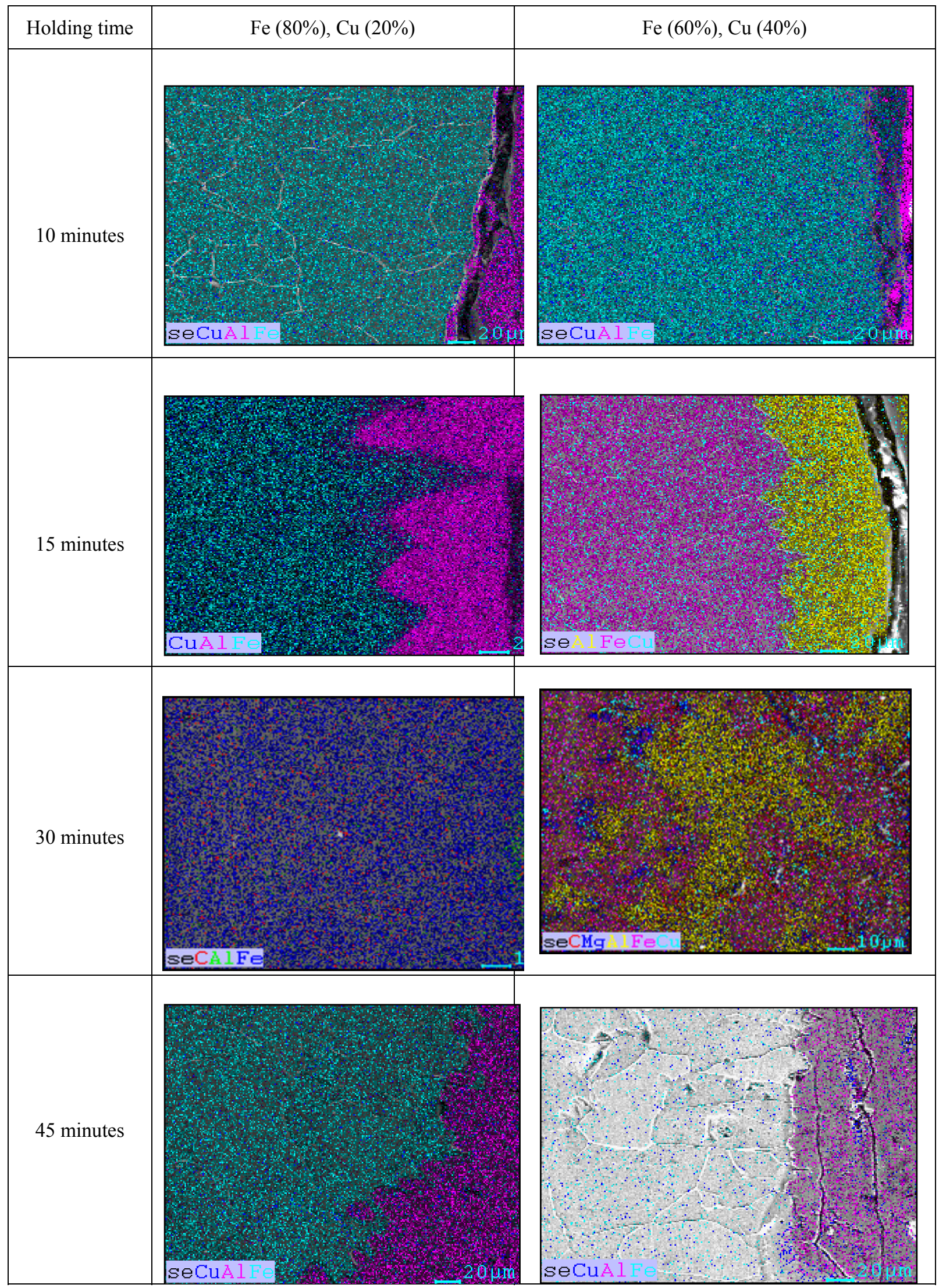

Figure 3. Elements mapping at steel side

At holding time in range of 10-30 minutes, it was found that in the interface there are incomplete bondings and 
cracks shown in Figure 2. There were visible cracks on the surface area with small interface layer in specimens with holding time of 10 minutes both the joints with element promoter composition of $60 \% \mathrm{Fe}-40 \% \mathrm{Cu}$ and $80 \% \mathrm{Fe}-20 \% \mathrm{Cu}$. It means that diffusion of aluminum into steel did not happen significantly with 10 minutes holding time. At 15 and 30 minutes holding time, the interface thickness increases with smaller gap and cracks. It was very clear in the figure that the solubility of aluminum increased with increasing of holding time where more aluminum dissolved into steel. The best results were found in specimens with composition of $60 \% \mathrm{Fe}-40 \% \mathrm{Cu}$ at 45 minutes holding time. In this case, diffused surface area increases because the diffusion of the composition occurs between aluminum and steel which interlock each other resulting in thick interface area and negligible cracking. Additionally, continous intermetalic layer appeared in this specimen, while it didn't appear in other specimens.

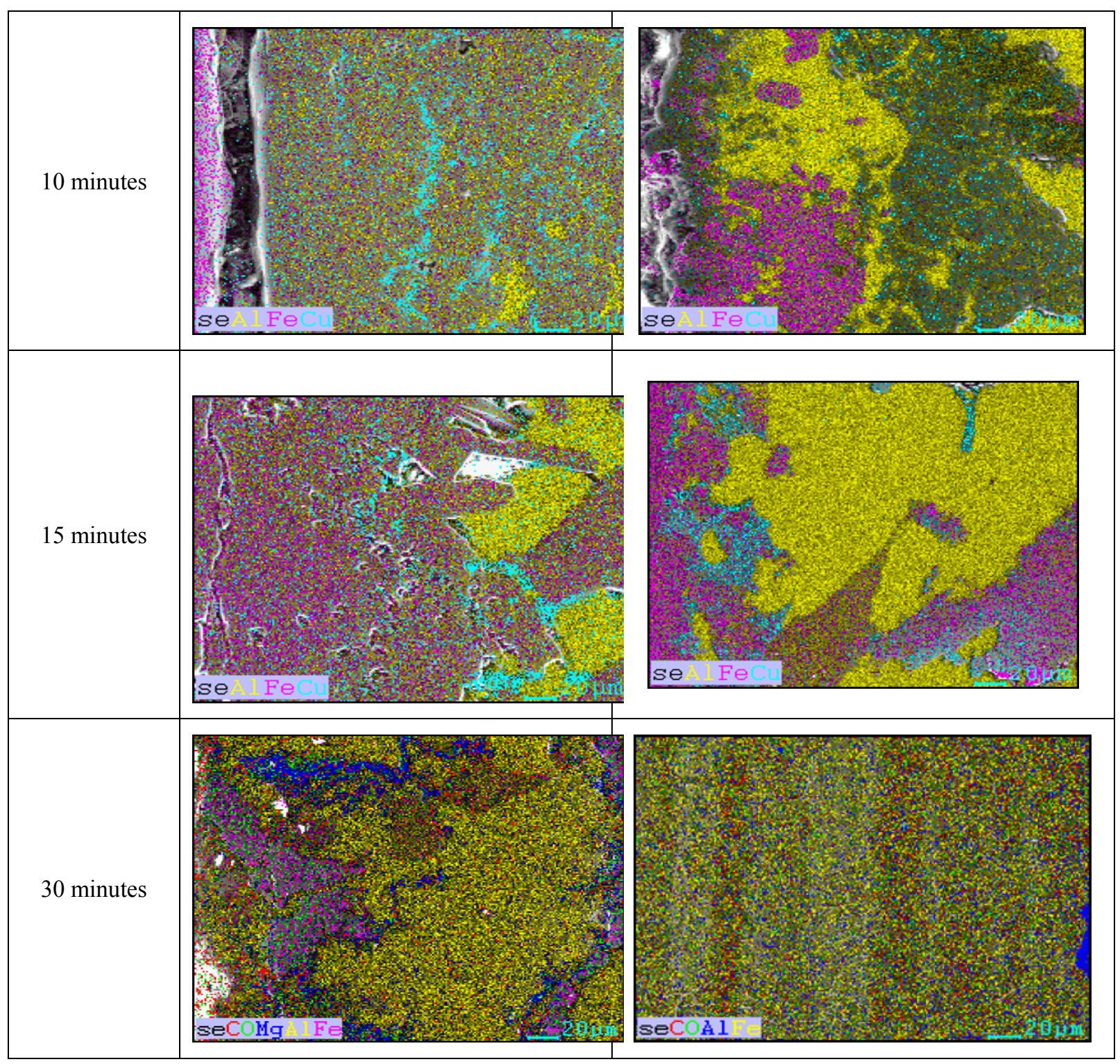




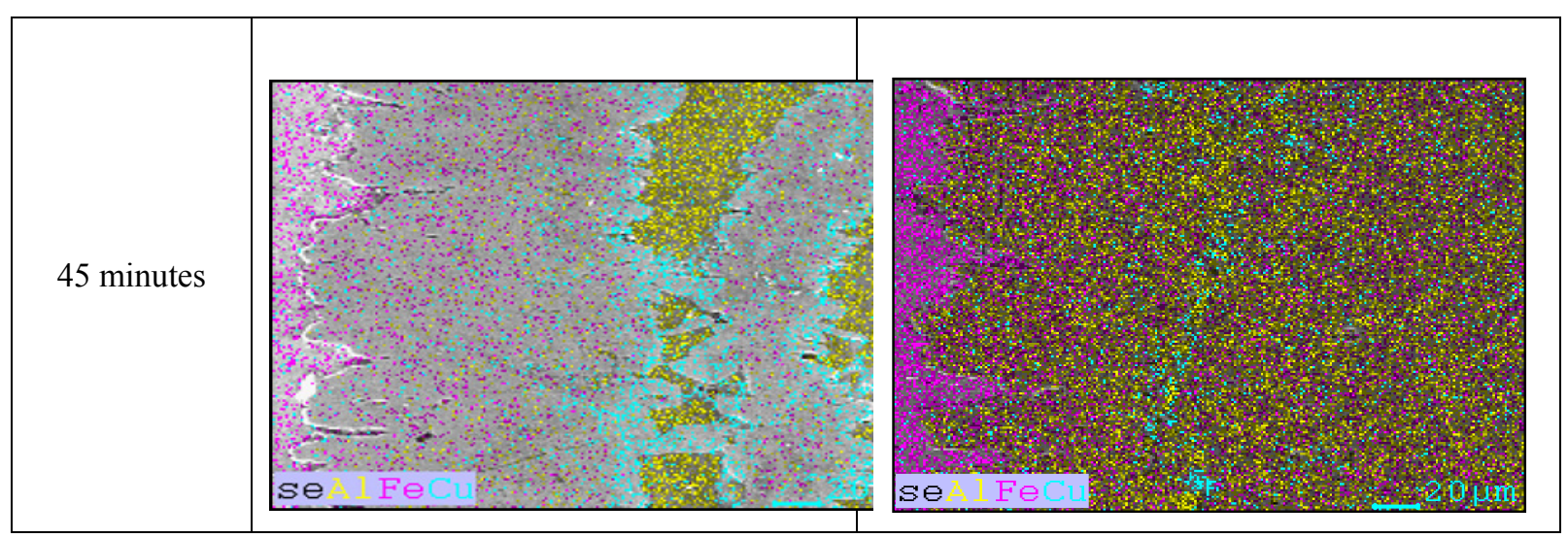

Figure 4. Elements mapping at aluminum side

Generally, thickness increased with increasing holding time. In case holding time up to 30 minutes, smal gap and cracks appeared as seen in macrostructure. The thickness of intermetalik layers increases linearly with increasing holding time but until holding time of 45 minutes. As holding time increased, the macro of the intermetalic layer displayed an increasing amount of intercellular primary aluminum solidification. Similar studies have also been carried out for the welding of aluminum and steel friction stir welding by Watanabe et al. (2006) and Rafeng et al (2009). The main results obtained form the studied on the microscopic structure, the strength of steel with aluminum, welding resistance were as follows. The maximum tensile strength of the joint was about $86 \%$ of that of the aluminum alloy base metal. A small amount of intermetallic compounds was formed at the upper part of the steel/aluminum interface, while no intermetalic compounds were observed in the middle and bottom parts of the interface.

Figure 3 and Figure 4 show the influence of holding time on inter-metallic gap between aluminum and carbon steel at two different $\mathrm{Fe}-\mathrm{Cu}$ combinations. The minimum crack between aluminum and carbon steel was found at combination with holding time 45 minutes whereas significant inter-metallic gap between aluminum and carbon steel was obtained both at $80 \% \mathrm{Fe}-20 \% \mathrm{Cu}$ and $60 \% \mathrm{Fe}-40 \% \mathrm{Cu}$ with holding time $10-30$ minutes.

Additionally, from the mapping point of view at $20 \mu \mathrm{m}$ it can be observed that $\mathrm{Cu}$ molecules are confined only the interface area and slightly scattered outside the inter-confront area in specimens with holding time up to 30 minutes both at $80 \% \mathrm{Fe}-20 \% \mathrm{Cu}$ and $60 \% \mathrm{Fe}-40 \% \mathrm{Cu}$. On the other hand, $\mathrm{Cu}$ molecules were scattered throughout the specimen with holding time of 45 minutes. It means $\mathrm{Cu}$ molecules play a vital role of identifying best $\mathrm{Al}-\mathrm{Fe}$ interface combination i.e. if the $\mathrm{Cu}$ molecules are located just around the inter-confront area that can be considered as a bad interface, whereas if the $\mathrm{Cu}$ molecules were scattered throughout interface zone that can be considered as a good interface

\section{Conclusion}

During diffusion process at $950^{\circ} \mathrm{C}$, the interfacial zone between aluminum and carbon steel substrate features intermetallic layers. The intermetallic thickness increased with increasing the holding time. Crack or incomplete bonding appeared on the specimens with holding time up to 30 minutes and didn't appear on the specimens with holding time of 45 minutes. $\mathrm{Cu}$ rich-element promoter made diffusion penetrated deeper than $\mathrm{Fe}$ rich-element promoter in the same holding time. Macrostructure, microstructure and SEM examinations revealed that Al-steel joint had the best result with element promoter content of $60 / 40 \%$ at 45 minutes holding time. There was no interlayer gap at this specimen. Additionally, from mapping view it can be suggested that in terms of poor interface bonding, $\mathrm{Cu}$ molecules were located just around the interface area, on the other hand, in case of strong interface bonding, $\mathrm{Cu}$ molecules are scattered throughout the specimen.

\section{Acknowledgments}

The authors would like to express their sincere gratitude for Ministry of Education and Culture of Indonesian Republic through MP3EI 2013 grant.

\section{Reference}

Kelkar, A. D., Mohan, R., Ghazizadeh, M., \& Kimbro, E. (2013). Progressive Failure Analysis of Hybrid Composite Laminates Under Static Tensile Loading. Journal of International Scientific Publications: 
Materials, Methods \& Technology, 7(1). Retrieved from http://www.scientific-publications.net/download/ materials-methods-and-technologies-2013-1.pdf

Dinaharan, K., Kalaiselvan, Vijay, S. J., \& Raja, P. (2012). Effect of Material Location and Tool Rotational Speed on Microstructure and Tensil Strength of Dissimilar Friction Stir Welded Aluminium Alloy. Archives of Civil and Mechanical Engineering, 12, 446-456. http://dx.doi.org/10.1016/j.acme.2012.08.002

Khan, A. S., Kazmi, R., Pandey, A., \& Stoughton, T. (2009). Evolution of subsequent yield surfaces and elastic constants with finite plastic deformation. Part-I: A very low work hardening aluminum alloy (Al6061-T6511). International Journal of Plasticity, 25(9), 1611-1625. http://dx.doi.org/10.1016/j.ijplas.2008.07.003

Khan, A. S., Pandey, A., \& Stoughton, T. (2010). Evolution of subsequent yield surfaces and elastic constants with finite plastic deformation. Part II: A very high work hardening aluminum alloy (annealed $1100 \mathrm{Al}$ ). International Journal of Plasticity, 26(10), 1421-1431. http://dx.doi.org/10.1016/j.ijplas.2009.07.008

Khan, A. S., Pandey, A., \& Stoughton, T. (2010). Evolution of subsequent yield surfaces and elastic constants with finite plastic deformation. Part III: Yield surface in tension-tension stress space (Al 6061-T 6511 and annealed $1100 \mathrm{Al}$ ). International Journal of Plasticity, 26(10), 1432-1441. http://dx.doi.org/10.1016/j.ijplas. 2009.07.007

Kim, K. H., van Daele, B., Van Tendeloo, G., \& Yoon, J. K. (2006). Observations of intermetallic compound formation of hot dip aluminized steel. In Materials science forum (Vol. 519, pp. 1871-1876). Retrieved from http://www.scientific.net/MSF.519-521

Kobayashi, S., \& Yakou, T. (2002). Control of intermetallic compound layers at interface between steel and aluminum by diffusion-treatment. Materials Science and Engineering: A, 338(1), 44-53. http://dx.doi.org/10.1016/S0921-5093(02)00053-9

Maea, H., Tengb, X., Baib, Y. \& Wierzbickib, T. (2008). Comparison of ductile fracture properties of aluminum castings: Sand mold vs. metal mold. International Journal of Solids and Structures, 45(5), 1430-1444. http://dx.doi.org/10.1016/j.ijsolstr.2007.10.016

Mahendran, G., Balasubramanian, V., \& Senthilvelan, T. (2010). Influences of diffusion bonding process parameters on bond characteristics of $\mathrm{Mg}-\mathrm{Cu}$ dissimilar joints. Transactions of Nonferrous Metals Society of China, 20(6), 997-1005. http://dx.doi.org/10.1016/S1003-6326(09)60248-X

Patel, A. S, Neerajd S., \& Bhavin, K. (2013). Asktom.oracle.com (Volume 1, Issue 11).

Qiu, R., Satonaka, S., \& Iwamoto, C. (2009). Effect of interfacial reaction layer continuity on the tensile strength of resistance spot welded joints between aluminum alloy and steels. Materials \& Design, 30(9), 3686-3689. http://dx.doi.org/10.1016/j.matdes.2009.02.012

Sun, X., \& Khaleel, M. A. (2007). Dynamic strength evaluations for self-piercing rivets and resistance spot welds joining similar and dissimilar metals. International journal of impact engineering, 34(10), 1668-1682. http://dx.doi.org/10.1016/j.ijimpeng.2006.09.092

Watanabe, T., Takayama, H., \& Yanagisawa, A. (2006). Joining of aluminum alloy to steel by friction stir welding. Materials Processing Technology, 178, 342-349.

Yajiang, L., Wang J., Yin, Y. S., \& Ma, H. J. B. (2005). Diffusivity of Al and Fe near the diffusion bonding interface of Fe3Al with low carbon steel. Mater. Sci., 28(1), 69-74. http://dx.doi.org/10.1016/j.jmatprotec. 2006.04.117

\section{Copyrights}

Copyright for this article is retained by the author(s), with first publication rights granted to the journal.

This is an open-access article distributed under the terms and conditions of the Creative Commons Attribution license (http://creativecommons.org/licenses/by/3.0/). 